\title{
High-frequency epicardial ultrasound: review of a multipurpose intraoperative tool for coronary surgery
}

\author{
Ricardo P. J. Budde · Patricia F. A. Bakker • \\ Paul F. Gründeman · Cornelius Borst
}

Received: 7 March 2008/ Accepted: 25 June 2008/Published online: 20 September 2008

(C) The Author(s) 2008. This article is published with open access at Springerlink.com

\begin{abstract}
Background In open-chest coronary artery bypass grafting $(\mathrm{CABG})$, the surgeon faces several intraoperative challenges: (1) to locate the target coronary artery, (2) to select the optimal anastomotic site, and (3) to assess the quality of the graft and distal anastomosis. Endoscopically, these three diagnostic aims are particularly challenging.

Methods We reviewed the literature on the intraoperative application of high-frequency $(6.5-15 \mathrm{MHz})$ epicardial ultrasound (ECUS) in CABG to aid in these challenges. Results Overall, ECUS was used in 628 patients to visualize and assess 912 (segments of) coronary arteries, as well as 418 grafts and distal anastomoses. In 96 cases, ECUS successfully located a coronary artery that was buried in the epicardial and/or myocardial tissue. In 37/155 (24\%) imaged anastomotic sites, an alternative site free of pathology was selected. For quality assessment of the coronary anastomosis, experimental validation of ECUS included 218 anastomoses in ex vivo and animal models. ECUS showed high sensitivity (0.98) and specificity (1.00) for detection of anastomotic construction errors in $120 \mathrm{ex}$ vivo anastomoses. In 418 grafts and distal anastomoses evaluated in patients, irregularities leading to revision were detected in $8(1.9 \%)$ anastomoses and minor irregularities in an additional $23(5.5 \%)$ anastomoses. However, little is known about the effect on long-term patency of specific
\end{abstract}

R. P. J. Budde $(\bowtie)$ · P. F. A. Bakker · P. F. Gründeman · C. Borst

Heart Lung Center Utrecht, University Medical Center Utrecht (Room G02.523), Heidelberglaan 100, 3584 CX Utrecht, The Netherlands

e-mail: rbudde@umcutrecht.nl anastomotic abnormalities revealed by ECUS. Scanning of arteries and anastomoses required several minutes. Current size ultrasound probes allowed successful experimental robot-assisted endoscopic application of ECUS.

Conclusions CABG may be facilitated and improved in several ways by intraoperative high-frequency epicardial ultrasound scanning. Totally endoscopic CABG may benefit from ultrasound diagnostics in particular.

Keywords Cardio - Quality control · Radiology · Ultrasonography · Thoracoscopy

During coronary artery bypass grafting (CABG), the surgeon faces several intraoperative challenges: (1) to target coronary artery localization, (2) selection of the optimal anastomotic site on the coronary artery, and (3) quality assessment of the constructed anastomosis. These challenges are greatly augmented by the complexity of totally endoscopic CABG (TECABG).

High-frequency $(6.5-15 \mathrm{MHz})$ epicardial ultrasound (ECUS) may help the surgeon to deal with these challenges. Its use was first reported in the 1980s [1-6]. At that time, however, bulky transducers limited their use to the anterior side of the heart, which prevented widespread adoption and application [1-6]. In the 1990s, renewed interest in the technique was sparked by the development of off-pump [7] and minimally invasive [8] approaches for CABG in which the surgical challenges are more pronounced, as well as by the introduction of smaller transducers [9-32].

We reviewed the literature on ECUS in CABG surgery to summarize the combined experience and determine its current status. 


\section{Materials and methods}

\section{Search strategy}

An English-language literature search using Pubmed/Medline databases was performed on the application of ECUS for coronary artery and anastomosis assessment using combinations of the following keywords: "ultrasound", "echocardiography", "epicardial", "coronary artery bypass", "anastomosis", and “coronary artery". Potentially suitable articles were retrieved and reviewed for relevance. The reference lists of included articles were reviewed for additional relevant articles not found with the online search. To exclude double reporting, intraoperative patient data reported in both a baseline and follow-up article was retrieved from the baseline article only. Articles summarizing previously published data from a single research group were excluded when the original articles were included.

\section{Results}

Thirty publications on ECUS were included in this review; 21 contained solely clinical data, 5 solely laboratory data, and 4 a combination of clinical and laboratory data. The combined results in 628 patients to assess a total of 912 (segments of) coronary arteries and 418 grafts and distal anastomoses are reported [1-6, 9, 11-18, 20-24, 29-32], as well as experimental validation in animal and ex vivo experiments of 60 coronary arteries and 218 anastomoses $[1,2,10,17,25-28]$. Owing to the heterogeneity of the studies, the review does not include a meta-analysis of the reported findings.

Epicardial ultrasound equipment

\section{Imaging frequency}

Detailed visualization of the small $(<2 \mathrm{~mm})$ coronary arteries requires linear array transducers with relatively high imaging frequencies $(6.5-15 \mathrm{MHz})$, in between transesophageal (TEE, 5-7.5 MHz) and intravascular (30$40 \mathrm{MHz}$ ) ultrasound probes. The phantom resolution of 6.5-15 MHz probes is in the range of 0.1 to $0.25 \mathrm{~mm}$, with approximately $4 \mathrm{~cm}$ penetration depth [2-6, 11, 17-19, 27].

\section{Transducer size}

Transducer size gradually decreased from rod-shaped transducers as large as $24 \times 2.5 \mathrm{~cm}$ that were used in the pioneering 1980s studies [2-4] to (mini-) transducers as small as $1.5 \times 0.9 \times 0.6 \mathrm{~cm}[10,12,13,15-17,20-30]$ (Fig. 1A). These mini-transducers can reach all parts of the heart [29] and easily fit between the suction pods of a coronary stabilizer $[21,22]$. Some can pass through a trocar for endoscopic use (Fig. 1C) [25, 26].

\section{Handling tool}

An adjustable handling tool (Fig. 1B) facilitates access to each individual target site on the heart [29]. Rigid handles integrated with the probe housing may hamper optimal positioning, especially on the posterior side of the heart [32]. A custom-made snap-on probe holder enables endoscopic manipulation with robotic instruments (Fig. 1C).

\section{Optimal conditions for scanning}

Visualization (using both B-mode and color Doppler imaging) is ideally performed on the beating heart with the use of a stabilization device because this best represents the physiologic pressure and flow in the coronary artery and anastomosis [17, 21, 22]. Without stabilization, imaging of the beating heart is more difficult and prone to motion artefacts [1, 14, 26]. In CABG on the arrested heart, scanning may be performed during cardioplegia perfusion [3, 14, 29]. Color Doppler imaging, however, is less informative in this setting. Care must be taken to ensure a sufficiently high perfusion pressure, and arteries should not be compressed during dislocation [29]. Warm saline in the pericardial sac, sterile gel or a stand-off pad applied onto the epicardial surface are used for improved contact and near-field imaging [2-4, 12, 14, 20, 21, 24, 29].

Standard monitors on ultrasound systems are usually relatively small and the use of a second, larger monitor that can be optimally positioned for the surgeon is recommended. In TECAB, picture-in-picture technology is used to integrate the endoscopic and ultrasound images at the surgeon console (Fig. 2).

\section{Time consumption}

Target coronary artery localization and/or assessment required less than one to several minutes [3, 17, 20, 29, 30]. Anastomosis visualization and assessment in open-chest cases is reported to take approximately $1 \mathrm{~min}$ by Hiratzka et al. [2] and Suematsu et al. [17], and a median of 150s (range 54-335s) by Budde et al. [29]. In another early study by Hiratzka et al. [4], generally less than 5 min was required per anastomosis. Robot-assisted endoscopic coronary artery localization required less than $1 \mathrm{~min}$ and anastomosis assessment approximately $2 \mathrm{~min}$ in a closedchest, endoscopic off-pump pig model [26]. 

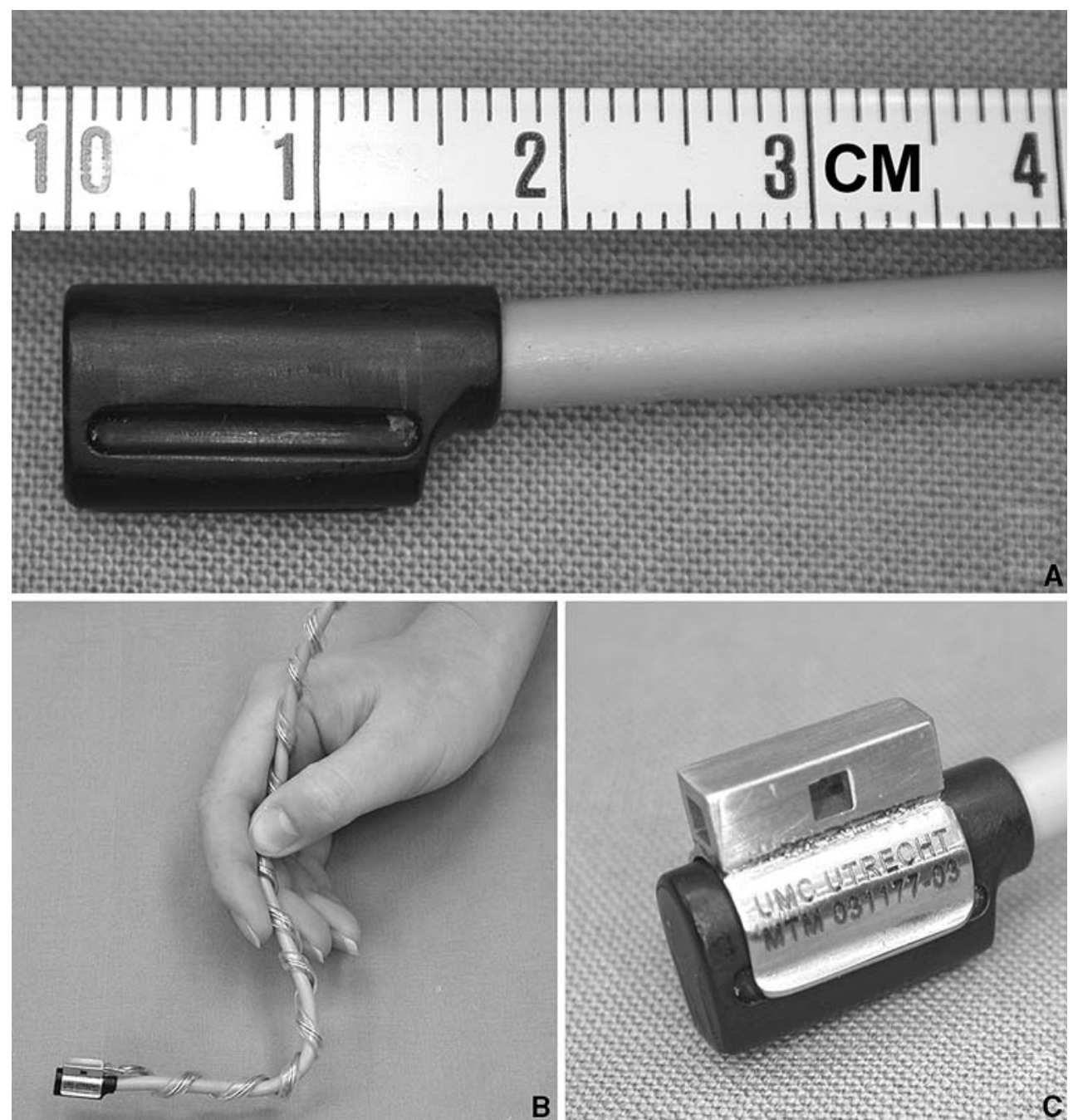

Fig. 1 Epicardial ultrasound mini-transducer. (A) mini-transducer with ruler $(\mathrm{cm})$; $(\mathbf{B})$ malleable handling tool that can be bent into any desired configuration; (C) snap-on probe handling tool that can be easily handled by the end-effectors of a robotic surgery system during endoscopic use

\section{Safety}

The transducer needs to be placed in a sterile cover or to be sterilized [1-6, 12, 14, 16-22, 29]. In the latter case, the imaging system must have a cardio-flux mark (indicating testing to high standards regarding leakage currents). Alternatively, the sterile cover can also act as an electrical barrier [29].

Application 1: localization and identification of the target coronary artery

\section{Conventional localization and identification}

A thick layer of epicardial fibro-fatty tissue, an intramyocardial vessel course, and/or fibrosis will make intraoperative visual localization of coronaries difficult. Inadvertent grafting of the wrong vessel [often a diagonal branch instead of the left anterior descending coronary artery (LAD)] is reported in up to $3 \%$ of grafts [33]. If visual localization is not possible, timeconsuming and potentially dangerous dissection of the epicardial and myocardial tissue is needed, with the risk of bleeding and/or entering the ventricular cavities. In totally endoscopic $\mathrm{CABG}$, inability to locate the coronary artery led to conversion in up to $9 \%$ of patients [34].

\section{Localization and identification by ECUS}

Clinical studies reporting on coronary artery visualization by ECUS are summarized in Table 1. Ninety-six cases of successful coronary artery localization with ECUS when conventional localization failed have been described [3, 9, 15, 24, 29, 32]. Localization by ECUS took only a few minutes and allowed targeted dissection of the epicardial fat, minimizing risk and time consumption [3, 17]. For LAD identification, the underlying ventricular septum and the 


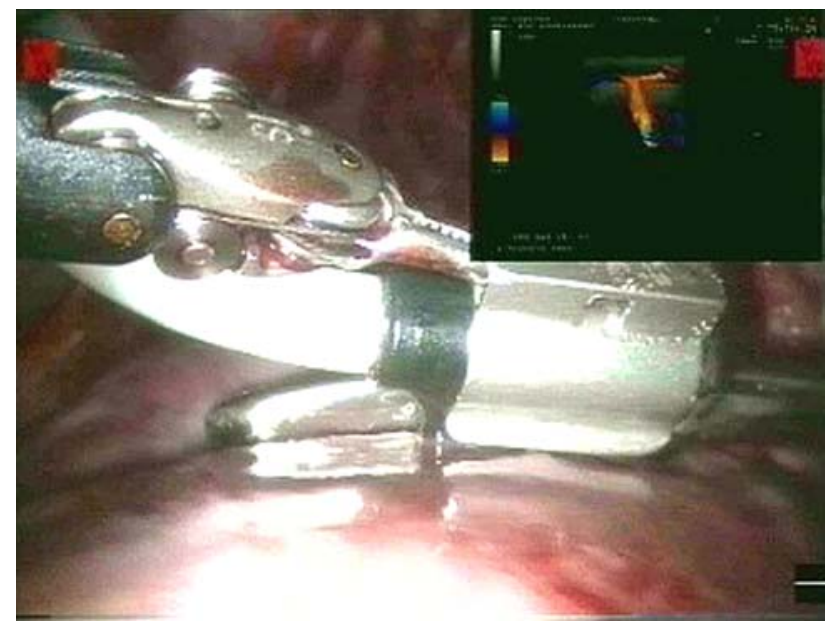

Fig. 2 Surgeon's view on the master console of the robot system during scanning of the LAD in the endoscopic porcine CABG model. The ECUS mini-transducer is positioned using the end effector of the robotic instrument. The EndoOctopus suctionpod is positioned on the epicardium behind the ultrasound transducer. The real-time ultrasound image is displayed as a picture-in-picture in the upper right hand corner, which allows direct integration of the location of the probe and the visualized structures. (Reprinted with permission from Budde et al. (2008) Medical Robotics, I-Tech Education and Publishing, Vienna, Austria)

presence of septal perforators serve as distinctive echocardiographic landmarks [15, 29]. Arteries can be discriminated from accompanying veins by the presence of calcifications and plaque and in color Doppler imaging, by the different color filling due to opposite flow directions [3, 22, 25]. Furthermore, veins are more easily compressed than arteries when applying gentle pressure with the transducer.

Using ECUS, unintended grafting of a diagonal branch that was erroneously identified by conventional selection as the LAD was prevented [29].

In animal models robot-assisted ECUS was successfully used endoscopically to locate the major arteries for bypass grafting [25].

Application 2: optimal anastomotic site selection

\section{Conventional site selection}

Intraoperatively, the surgeon uses visual information and palpation to detect the angiographic stenosis and select the anastomotic site. Not all stenotic sites may be accurately depicted on the angiogram [1] and digital palpation is subjective and may easily miss soft plaques, especially on the posterior vessel wall. Therefore, the anastomotic site may appear suboptimal after the artery is opened.

In off-pump CABG, in addition, the coronary artery needs to be clamped during anastomosis suturing. Backbleeding through the arteriotomy from septal perforators and side branches in the isolated coronary segment may severely hamper visibility of the suture line. Septal perforators cannot be detected conventionally before opening the vessel.

Table 1 Summary of data from studies reporting on coronary artery visualization by ECUS

\begin{tabular}{|c|c|c|c|c|c|}
\hline Author & No. of patients & No. off-pump & $\begin{array}{l}\text { No. of coronary } \\
\text { arteries visualized }\end{array}$ & $\begin{array}{l}\text { No. of deeply buried } \\
\text { arteries located by ECUS }\end{array}$ & $\begin{array}{l}\text { ECUS-induced deviation } \\
\text { from original anastomotic site }\end{array}$ \\
\hline Hiratzka [3] & 2 & 2 & 2 & 2 & - \\
\hline Mc Pherson [5] & 47 & 0 & 97 segments & - & - \\
\hline Isringhaus [9] & 112 & 0 & 588 segments & 50 arteries & $25 / 112$ \\
\hline Mc Pherson [11] & 24 & 0 & 68 segments & - & - \\
\hline Kenny [12] & 29 & 0 & 29 & - & - \\
\hline Oda [15] & 5 & 5 & 5 & 5 & - \\
\hline Suematsu [17] & 12 & 12 & 12 & $-{ }^{\mathrm{b}}$ & $3 / 12$ \\
\hline Haaverstad [20] & 23 & 0 & 20 & - & - \\
\hline Eikelaar [22] & 13 & 13 & 13 & - & $3 / 13$ \\
\hline Miwa [24] & 6 & 6 & 6 & 6 & - \\
\hline Budde [29] & 8 & 0 & 8 & 1 & $4 / 8$ \\
\hline Stein [30] & 10 & 5 & 10 & - & $2 / 10$ \\
\hline Schiller [32] & 32 & 19 & $54^{\mathrm{c}}$ & 32 & - \\
\hline Total & 323 & $62(19 \%)$ & $\begin{array}{l}753 \text { segments }+ \\
159 \text { arteries ( } 912 \text { total) }\end{array}$ & 96 & $37 / 155(24 \%)$ \\
\hline
\end{tabular}

Some studies report on other applications of ECUS as well, hence the patient number is larger than the number of arteries assessed for some studies. ${ }^{a}$ Presented as number of site changes per total number of sites assessed for this purpose; ${ }^{\mathrm{b}}$ Mentioned that deeply located arteries could be found (no numbers given); ${ }^{\mathrm{c}}$ Number of successfully imaged arteries; an additional 19 could not be visualized due to the rigid probe handle. All patients were operated through a sternotomy approach, except the five patients from [15] 


\section{Site selection with ECUS}

With ECUS, the quality of the target coronary artery can be rapidly and accurately assessed $[1,3,5,9,11,12,15$, $17,20,22,24,29,30,32]$. Measurement of the coronary lumen (as well as the internal mammary artery for size matching) by ECUS correlates well with both histological and angiographic dimensions $[1,5,11,17,19,20]$. Plaque, calcifications and side branches are easily seen. Epicardial ultrasound is especially helpful to assess those sections that are not well visualized on the angiogram (Fig. 3) [1, 29]. By assessing the degree of stenosis and distal runoff, intraoperative assessment by ECUS helps to decide whether or not and where to graft the target artery $[6,9,29]$. In off-pump cases, ECUS may be used to locate and excluded septal perforators from the isolated coronary segment [22].

\section{Intraoperative change of anastomotic site}

Deviation from the initial, conventionally selected anastomotic site after ECUS scanning is described in a combined $37 / 155$ cases $(24 \%)$ [9, 17, 22, 29, 30]. Anastomotic site change in $24 \%$ of cases is remarkable. As a result, it is conceivable that a number of anastomosis irregularities seen on postoperative angiography are actually due to selection of suboptimal anastomotic sites, rather than to suture errors. Evidence for this hypothesis was provided by the detection of a large calcification, just distal to the anastomosis, during ECUS scanning of the anastomosis in a patient in whom pre-arteriotomy scanning of the coronary artery was not performed, but would have allowed deviation to a more distal site, free of pathology [29].
Indications for coronary artery assessment by ECUS

The indications for coronary artery assessment by ECUS include: a difficult to interpret angiogram (including questions regarding the angiographic degree of stenosis in general and for radial artery grafts specifically), extensive epicardial fat, an intramural vessel course, diffuse coronary artery disease, and discrepancies between preoperative angiographic and intraoperative findings. Additional indications in endoscopic cases include limited overview and difficult to interpret anatomical landmarks.

Application 3: quality control of the constructed anastomosis

\section{Graft patency}

According to a review by Mack et al. [35], the long-term (up to 15 years) angiographic left internal mammary artery (LIMA) to LAD patency varies between $51 \%$ and $98 \%$. Patency is a nonspecific term, because it does not provide information on the degree of stenosis. Berger et al. [36] studied the angiographic LIMA-LAD patency at short-term follow-up (mean 10.8 days) in 617 patients undergoing CABG on the arrested heart via a median sternotomy. Patency was $98.7 \%$, but only $91 \%$ of grafts had $\leq 50 \%$ stenosis [36]. In a recent large trial [37], the vein graft occlusion rate at $12-18$ months postoperatively was $26.5 \%$ on a per-graft basis and $41.7 \%$ on a per-patient basis. Using intraoperative angioscopy, (minor) irregularities are detected in up to $24 \%$ of anastomoses [38].

Several alternative techniques for intraoperative anastomosis assessment have been described, including angiography, transit-time flowmetry, fluorescence imaging,
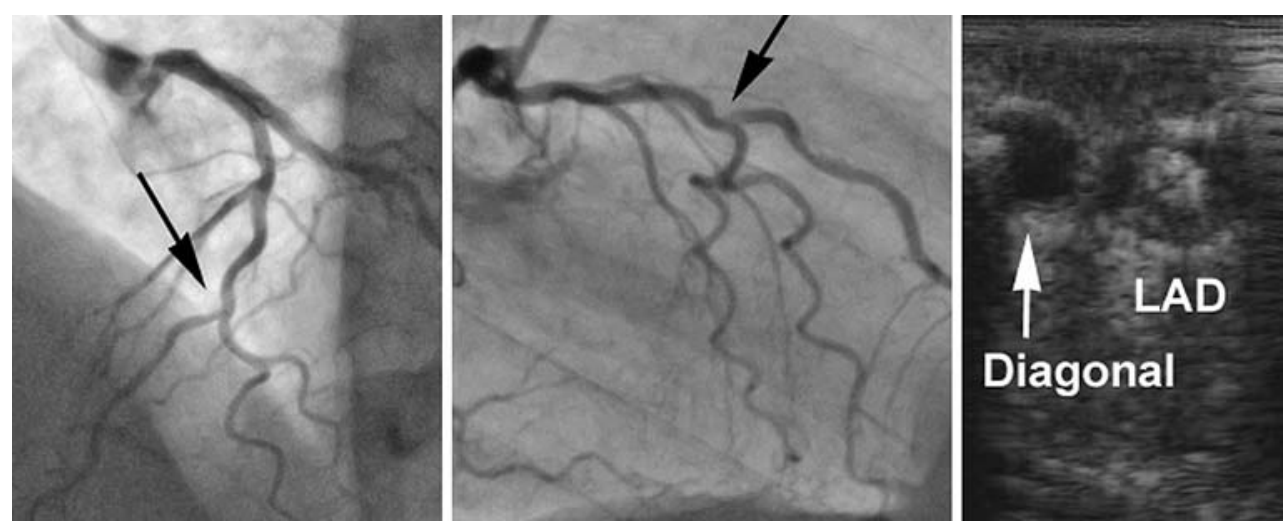

Fig. 3 Preoperative angiogram [left anterior oblique view (left panel) and right anterior oblique view (middle panel)] and corresponding intraoperative transverse epicardial ultrasound image (right panel). Preoperatively, uncertainty existed regarding a possible stenosis at the origin of the diagonal branch (black arrow) in this patient. The transverse epicardial ultrasound image (at the level of the black arrow) of the left anterior descending coronary artery (LAD) and diagonal branch just distal to its origin revealed substantial wall pathology in the LAD, rather than in the diagonal. Hence, the LAD was grafted 
thermal imaging, and angioscopy [31, 33, 38-40]. Owing to its ease of use, transit-time flowmetry is probably most commonly used. However, only a zero flow indicates a totally occluded graft whereas no clear cutoff values for abnormal graft flow have been firmly established, which prevented widespread acceptance. Angiography is the clinical gold standard but is invasive, costly, time consuming, and the equipment is not available in most operating rooms. None of the other techniques can be used endoscopically.

\section{Anastomosis revision}

Data regarding intraoperative anastomosis revision are limited and vary widely (between $0.6 \%$ and $8.5 \%$ revision of all anastomoses) [40]. When taken as the percentage of patients in whom at least one anastomosis was revised, the numbers are between $2 \%$ and $8.5 \%$ of patients [40]. In $\mathrm{TECAB}$, the anastomotic suturing process is technically much more demanding, and anastomotic revision is needed in up to $11 \%$ of patients $[34,41]$.

Goldman and co-workers [42] showed that, if an internal mammary artery graft is patent at 1 week, it has a chance of $88 \%$ to be patent at 10 years. Thus, it is likely that intraoperative anastomotic quality assessment will help to increase anastomotic patency, as suboptimal anastomoses can be revised before chest closure.

\section{Validation of ECUS for anastomosis quality assessment}

In the 1980s, the potential of ECUS to assess anastomosis quality was recognized simultaneously with its value for target coronary artery assessment [1, 2]. Highly detailed images of the anastomosis can be obtained (Fig. 4), in which even individual sutures (7-0 Prolene) may be identified [28].

Validation in ex vivo and animal studies includes 218 anastomoses [2, 17, 26-28]. Based on evaluation of 120 anastomoses on ex vivo porcine and human hearts (using angioscopy and cast injection as reference), ECUS has high sensitivity (0.98) and specificity (1.00) for the detection of construction errors, which was significantly higher than achieved with the current gold standard angiography (sensitivity 0.75 , specificity 0.81 ) (Fig. 5) [28]. In animal studies ( $n=63$ anastomoses combined) [2, 17, 26], blinded observers using ECUS accurately discriminated anastomoses with deliberately introduced construction errors from all control anastomoses.

\section{Clinical anastomosis quality assessment}

Studies reporting on anastomosis quality assessment by ECUS are summarized in Table 2. Overall, 418 successfully visualized distal anastomoses and grafts have been reported (Fig. 6). In eight cases (1.9\%), the anastomosis was revised based on abnormal findings that included misplaced sutures, thrombus, dissection, and calcifications $[4,9,16,18,21]$. Other (minor) irregularities were seen in an additional 23 anastomoses (5.5\%) [2, 4, 18, 21, 29, 31]. So, overall, in $7.4 \%$ of examined anastomoses some form of irregularity was detected.

Dissection may be detected by ECUS [19]. Three cases, however, of internal mammary artery (IMA) dissection were detected by flowmetry [32] or intraoperative angiography [31] that ECUS failed to reveal.

Few data are available on ECUS findings and clinical follow up. Tjomsland and colleagues [23] report 1 occlusion out of 20 LIMA-LAD anastomoses assessed by angiography at median follow-up of 245 days. No abnormalities were observed intraoperatively by ECUS imaging.

Hol et al. [31] compared intraoperative ECUS with intra- and postoperative angiography (150 days, standard deviation [SD] 50 days) for assessment of 39 IMA-LAD anastomoses. ECUS detected five abnormalities, deemed not to require anastomosis revision. Based on intraoperative angiography, three grafts were revised (IMA dissection, $n=2$ and LAD occlusion, $n=1$ ). At followup angiography, one graft was occluded. Intraoperatively,
Fig. 4 Epicardial ultrasound image of a fully patent left internal mammary artery to left anterior descending coronary artery anastomosis on an ex vivo human heart: longitudinal image (left panel) with corresponding transverse image (right panel) at the level of the arrowhead. In the longitudinal image, the proximal part of the coronary artery is on the left. Note the distinct figure-of-eight geometry of the anastomosis in the transverse image

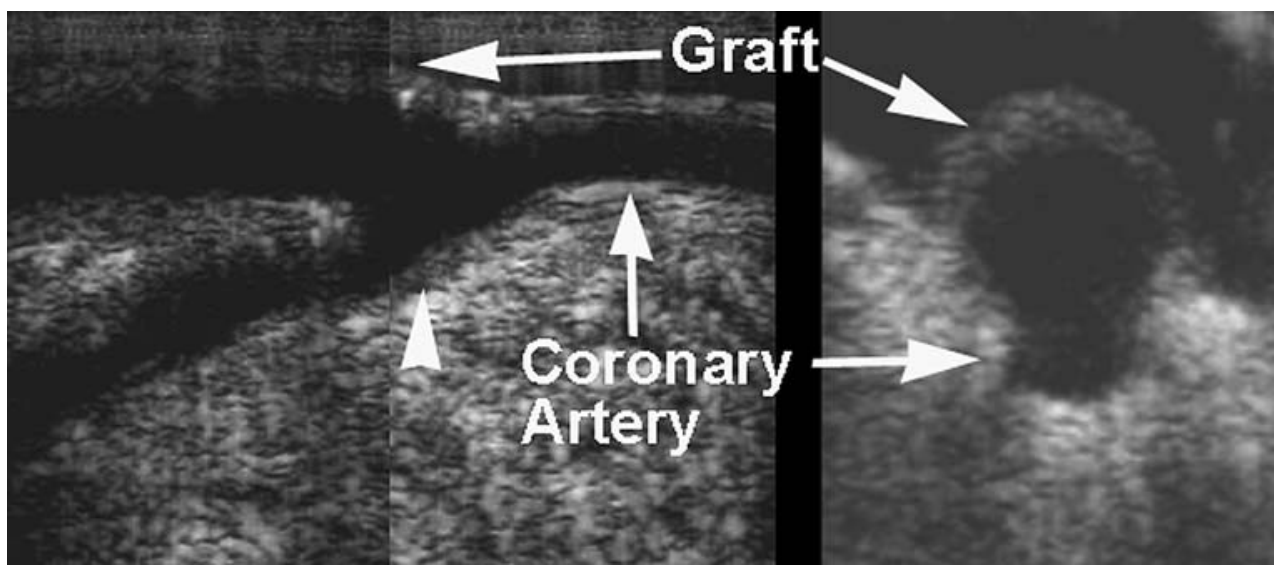




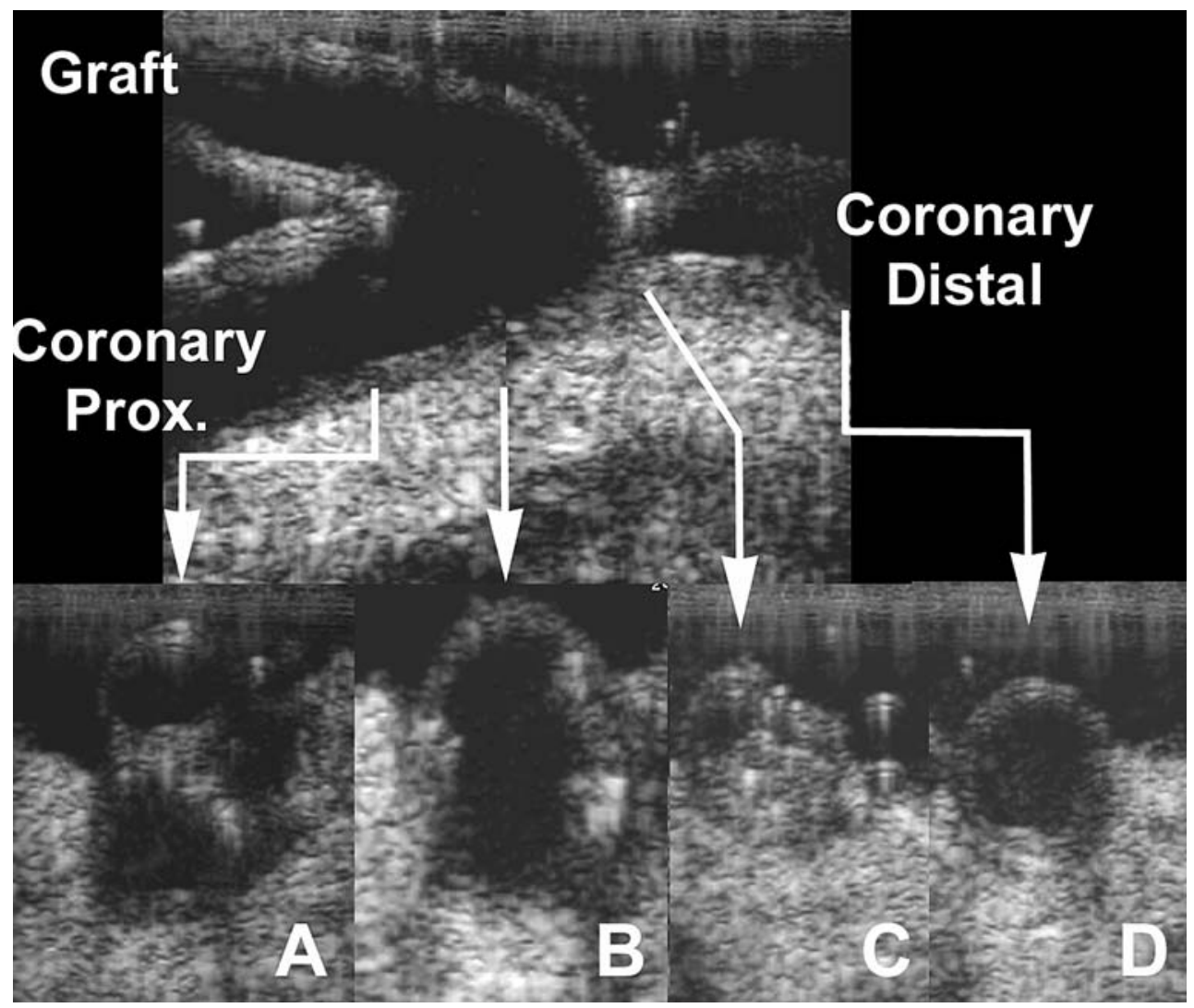

Fig. 5 Epicardial ultrasound image of stenosed left internal mammary artery to left anterior descending coronary artery anastomosis on an ex vivo human heart: longitudinal image with corresponding transverse images at the level of $(\mathbf{A})$ inflow corner, $(\mathbf{B})$ middle of the

this anastomosis was scored as fully patent by both ECUS and angiography. This illustrates that larger patient studies with structured angiographic and clinical follow-up are needed to determine which ECUS findings will predict a flow-limiting stenosis or anastomosis occlusion at followup and hence justify intraoperative anastomosis revision.

\section{Concerns}

\section{Operator dependency}

There is some concern about the operator dependency and subjectivity of epicardial ultrasound [39]. On the ex vivo heart, two experienced ultrasound observers independently scanned and subsequently scored 120 anastomoses identically (kappa 1.00) [28]. Thus, in experienced hands, epicardial ultrasound evaluation appears reproducible and operator independent.

\section{Costs}

The initial investment depends on whether a suitable ultrasound system (approximately US \$45,000-100,000, anastomotic orifice, $(\mathbf{C})$ outflow corner, and (D) the coronary artery distal to the anastomosis. Note the severe outflow corner stenosis caused by an intentionally misplaced stitch capturing the posterior wall of the coronary artery. Prox.: proximal

depending on type and manufacturer) is already available for other applications (e.g., TEE). If so, only an ECUS probe (approximately US $\$ 15,000$ ) needs to be purchased. The added procedural costs per patient consist of the cost per use for the ultrasound system and probe, the sterile ultrasound transmission gel and probe cover (approximately $\$ 70$, if required), and the additional operative time. These costs may be balanced by savings due to the anticipated lower rate of cardiovascular complications.

\section{Emerging applications}

\section{Coronary connector anastomosis}

Intraoperative anastomosis quality assessment may aid in the introduction of novel automated distal anastomosis connectors developed to facilitate the suturing process in minimally invasive approaches [43-45]. In the off-pump CABG pig model, ECUS was successfully used for quality assessment of a coronary connector anastomosis [45]. Connectors that contain a substantial amount of metal [43], however, may generate too many imaging artefacts to allow adequate assessment of anastomosis geometry. 
Table 2 Summary of data from studies reporting on anastomotic quality control by ECUS

\begin{tabular}{|c|c|c|c|c|c|}
\hline Author & No. of patients & No. off-pump & $\begin{array}{l}\text { No. of grafts or } \\
\text { distal anastomoses }\end{array}$ & $\begin{array}{l}\text { No. of revised } \\
\text { anastomoses }\end{array}$ & $\begin{array}{l}\text { No. of additional } \\
\text { abnormalities (not revised) }\end{array}$ \\
\hline Sahn [1] & 31 & 0 & 5 & 0 & 0 \\
\hline Hiratzka [2] & 12 & 0 & 15 & 0 & 2 \\
\hline Hiratzka [4] & 29 & 0 & 54 & 1 & 2 \\
\hline Isringhaus [9] & 112 & 0 & 45 & 4 & 0 \\
\hline Oda [13] & 15 & 1 & 15 & 0 & 0 \\
\hline Ishikura [14] & 31 & 0 & 8 & 0 & 0 \\
\hline Arruda [16] & 12 & 0 & 11 & 1 & 0 \\
\hline Suematsu [17] & 12 & 12 & 20 & 0 & 0 \\
\hline Suematsu [18] & 31 & 31 & 65 & 1 & 1 \\
\hline Haaverstad [20] & 23 & 0 & 26 & 0 & 0 \\
\hline Haaverstad [21] & 24 & 24 & 24 & 1 & 9 \\
\hline Eikelaar [22] & 13 & 13 & 13 & 0 & 0 \\
\hline Miwa [24] & 6 & 6 & 6 & 0 & 0 \\
\hline Budde [29] & 8 & 0 & 27 & 0 & 4 \\
\hline Stein [30] & 10 & 5 & 10 & 0 & 0 \\
\hline Hol [31] & 39 & 39 & 39 & 0 & 5 \\
\hline Schiller [32] & 32 & 19 & $35^{\mathrm{a}}$ & 0 & 0 \\
\hline Total & 440 & $150(34 \%)$ & 418 & $8(1.9 \%)$ & $23(5.5 \%)$ \\
\hline
\end{tabular}

Some studies report on additional applications of ECUS as well, hence the patient number is larger than the number of grafts and anastomoses assessed. ${ }^{\text {a }} 35$ anastomoses successfully imaged; another 38 anastomoses could not be imaged due to the rigid probe handle. All patients were operated through a sternotomy approach, except four patients from [17], seven patients from [18], and four patients from [32]

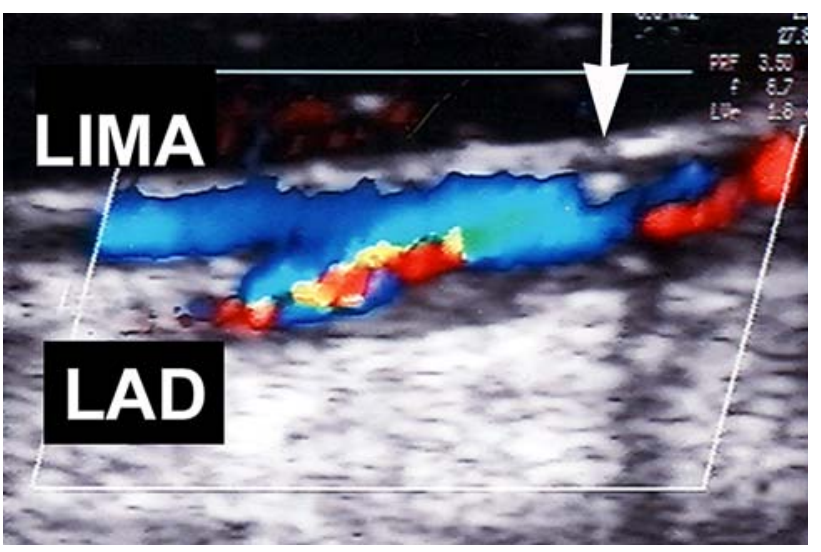

Fig. 6 Epicardial color Doppler ultrasound image of coronary anastomosis. Longitudinal epicardial color Doppler ultrasound image of a left internal mammary artery (LIMA) to left anterior descending coronary artery (LAD) anastomosis. Epicardial ultrasound scanning with a $13-\mathrm{MHz}$ mini-transducer revealed a slight stenosis of the LAD, just distal to the anastomosis, due to plaque in the anterior wall of the LAD (arrow). No scanning of the LAD was performed before anastomosis construction, which would have allowed selection of another site free of coronary disease. The image was kindly provided by Prof. R. Haaverstad, MD, PhD, Norway

\section{Discussion}

Current status and future directions

Since its introduction in the 1980s, ECUS has undergone substantial technical improvements and promising results have been published in recent years. The absence of its large-scale adoption we attribute to the following reasons: (1) no controlled evaluation in a large patient study has been performed yet; (2) despite current results, ECUS might still be considered an application restricted to the anterior side of the heart; (3) the time added by ECUS diagnostics might be overestimated; and (4) small vascular ultrasound probes are available, but not marketed specifically for ECUS application.

Surgeons may start using ECUS in selected patients (e.g., patients with new systolic wall motion abnormalities on TEE as the earliest indicator of myocardial ischemia) to gain experience using ECUS, and apply it routinely thereafter. Standardized intraoperative documentation by ECUS of graft patency may serve legal purposes as well.

None of the other anastomosis quality assessments techniques has currently gained widespread use and acceptance 
and studies with control intra- or postoperative angiography are emerging only slowly. ECUS may offer advantages over other anastomosis quality assessment techniques, because it is noninvasive, provides anatomical information, is inexpensive, can be used to evaluate the coronary artery before grafting, and is applicable endoscopically.

To determine the diagnostic value of ECUS, a large trial will be required in which detected irregularities have no consequences intraoperatively, but are correlated to follow-up angiography and clinical outcome. Comparison to intraoperative angiography would be the optimal setup but may be less realistic due the drawbacks of intraoperative angiography.

\section{Conclusions}

High-frequency epicardial ultrasound imaging may promise to become an effective multipurpose intraoperative diagnostic tool that is likely to benefit patients undergoing (TE)CABG surgery. However, it remains to be established whether the limited augmentation in operative time and treatment costs are balanced by the benefits to patient and surgeon.

Open Access This article is distributed under the terms of the Creative Commons Attribution Noncommercial License which permits any noncommercial use, distribution, and reproduction in any medium, provided the original author(s) and source are credited.

\section{References}

1. Sahn DJ, Barratt-Boyes BG, Graham K, Kerr A, Roche A, Hill D, Brandt PWT, Copeland JG, Mammana R, Temkin LP, Glenn W (1982) Ultrasonic imaging of the coronary arteries in open-chest humans: evaluation of coronary atherosclerotic lesions during cardiac surgery. Circulation 66:1034-1044

2. Hiratzka LF, McPherson DD, Lamberth WC Jr, Brandt B 3rd, Armstrong ML, Schröder E, Hunt M, Kieso R, Megan MD, Tompkins PK, Marcus ML, Kerber RE (1986) Intraoperative evaluation of coronary artery bypass graft anastomoses with highfrequency epicardial echocardiography: experimental validation and initial patient studies. Circulation 73:1199-1205

3. Hiratzka LF, McPherson DD, Brandt B 3rd, Lamberth WC Jr, Marcus ML, Kerber RE (1986) Intraoperative high-frequency epicardial echocardiography in coronary revascularization: locating deeply embedded coronary arteries. Ann Thorac Surg 42(6 Suppl):S9-11

4. Hiratzka LF, McPherson DD, Brandt B 3rd, Lamberth WC Jr, Sirna S, Marcus ML, Kerber RE (1987) The role of intraoperative high-frequency epicardial echocardiography during coronary artery revascularization. Circulation 76(suppl V):V33-V38

5. McPherson DD, Hiratzka LF, Lamberth WC, Brandt B, Hunt M, Kieso RA, Marcus ML, Kerber RE (1987) Delineation of the extent of coronary atherosclerosis by high-frequency epicardial echocardiography. N Eng J Med 316:304-309

6. Likungu J, Murdy H, Quade G, Kirchhoff P (1988) Intraoperative echocardiographic visualisation of coronary arteries, before and after aorto-coronary bypass grafting. Int $\mathrm{J}$ Card Imaging 3: $161-167$
7. Jansen EWL, Borst C, Lahpor JR, Gründeman PF, Eefting FD, Nierich A, Robles de Medina EO, Bredee JJ (1998) Coronary artery bypass grafting without cardiopulmonary bypass using the octopus method: results in the first one hundred patients. J Thorac Cardiovasc Surg 116:60-67

8. Diegeler A, Thiele H, Falk V, Hambrecht R, Spyrantis N, Sick P, Diederich KW, Mohr FW, Schuler G (2002) Comparison of stenting with minimally invasive bypass surgery for stenosis of the left anterior descending coronary artery. N Eng J Med 347:561-566

9. Isringhaus H (1990) Epicardial coronary artery imaging. Echocardiography 7:253-259

10. Kenny A, Fuller CA, Cary NRB, Shapiro LM (1991) Histopathological validation of high frequency epicardial echocardiography of the coronary arteries in vitro. Br Heart J 65:326-331

11. McPherson DD, Johnson MR, Collins SM, Kieso RA, Marcus ML, Kerber RE (1993) Validation by high-frequency epicardial echocardiography of a new method of analyzing coronary angiography quantitatively in coronary artery disease. Am J Cardiol 71:28-32

12. Kenny A, Shapiro LM (1994) Identification of coronary artery stenoses and poststenotic blood flow patterns using a miniature high-frequency epicardial transducer. Circulation 89:731-739

13. Oda K, Hirose K, Nishimori H, Sato K, Yamashiro T, Ogoshi S (1998) Assessment of internal thoracic artery graft with intraoperative color Doppler ultrasonography. Ann Thorac Surg 66:79-81

14. Ishikura F, Matsuwaka R, Sakakibara T, Sakata Y, Hirayama A, Kodama K (1998) Clinical application of power Doppler imaging to visualize coronary arteries in human beings. J Am Soc Echocardiogr 11:219-227

15. Oda K, Hirose K, Fukutomi T, Yamashiro T, Ogoshi S (1999) Intraoperative detection of embedded coronary arteries in MID$\mathrm{CAB}$ using a color Doppler microprobe. Ann Thorac Surg 68:263-264

16. Arruda AM, Dearani JA, Click RL, Ishikura F, Seward JB (1999) Intraoperative application of power Doppler imaging: visualization of myocardial perfusion after anastomosis of left internal thoracic artery to left anterior descending coronary artery. J Am Soc Echocardiogr 12:650-654

17. Suematsu Y, Takamoto S, Ohtsuka T (2001) Intraoperative echocardiographic imaging of coronary arteries and graft anastomoses during coronary artery bypass grafting without cardiopulmonary bypass. J Thorac Cardiovasc Surg 122:1147-1154

18. Suematsu Y, Ohtsuka T, Miyairi T, Motomura N, Takamoto S (2002) Ultrasonic evaluation of graft anastomoses during coronary artery bypass grafting without cardiopulmonary bypass. Ann Thorac Surg 74:273-275

19. Suematsu Y, Takamoto S, Ohtsuka T, Motomura N, Miyairi T (2002) Power Doppler imaging for detection of harvest injury of internal mammary artery. Asian Cardiovasc Thorac Ann 10:89-91

20. Haaverstad R, Vitale N, Williams RI, Fraser AG (2002) Epicardial colour-Doppler scanning of coronary artery stenoses and graft anastomoses. Scand Cardiovasc J 36:95-99

21. Haaverstad R, Vitale N, Tjomsland O, Tromsdal A, Torp H, Samstad SO (2002) Intraoperative color Doppler ultrasound assessment of LIMA-to-LAD anastomoses in off-pump coronary artery bypass grafting. Ann Thorac Surg 74:S1390-S1394

22. Eikelaar JHR, Meijer R, van Boven WJ, Klein P, Gründeman PF, Borst C (2002) Epicardial 10-MHz ultrasound in off-pump coronary bypass surgery: a clinical feasibility study using a minitransducer. J Thorac Cardiovasc Surg 124:785-789

23. Tjomsland O, Wiseth R, Wahba A, Tromsdal A, Samstad SO, Haaverstad R (2003) Intraoperative color Doppler ultrasound assessment of anastomoses of the left internal mammary artery to the left anterior descending coronary artery during off-pump 
coronary artery bypass surgery correlates with angiographic evaluation at the 8-month follow-up. Heart Surg Forum 6: 375-379

24. Miwa S, Nishina T, Ueyama K, Kameyama T, Ikeda T, Nishimura K, Komeda M (2004) Visualization of intramuscular left anterior descending coronary arteries during off-pump bypass surgery. Ann Thorac Surg 77:344-346

25. Budde RPJ, Meijer R, Bakker PFA, Borst C, Gründeman PF (2004) Endoscopic localization and assessment of coronary arteries by $13 \mathrm{MHz}$ epicardial ultrasound. Ann Thorac Surg 77:1586-1592

26. Budde RPJ, Dessing TC, Meijer R, Bakker PFA, Borst C, Gründeman PF (2004) Robot-assisted $13 \mathrm{MHz}$ epicardial ultrasound for endoscopic quality assessment of coronary anastomoses. Interactive Cardiovasc Thorac Surg 3:616-620

27. Dessing TC, Budde RPJ, Meijer R, Bakker PFA, Borst C, Gründeman PF (2004) Geometry assessment of coronary artery anastomoses with construction errors by epicardial ultrasound. Eur J Cardiothorac Surg 26:257-261

28. Budde RPJ, Meijer R, Dessing TC, Borst C, Gründeman PF (2005) Detection of construction errors in ex-vivo coronary artery anastomoses by $13 \mathrm{MHz}$ epicardial ultrasonography. J Thorac Cardiovasc Surg 129:1078-1083

29. Budde RPJ, Bakker PFA, Meijer R, Borst C, Gründeman PF (2006) Ultrasound mini-transducer with malleable handle for coronary artery surgery. Ann Thorac Surg 81:322-326

30. Stein H, Smith JM, Robinson JR, Katz MR (2006) Target vessel detection and coronary anastomosis assessment by intraoperative 12-MHz ultrasound. Ann Thorac Surg 82:1078-1084

31. Hol PK, Andersen K, Skulstad H, Halvorsen PS, Lingaas PS, Andersen R, Bergsland J, Fosse E (2007) Epicardial ultrasonography: a potential method for intraoperative quality assessment of coronary bypass anastomoses? Ann Thorac Surg 84:801-807

32. Schiller W, Rudorf H, Tiemann K, Probst C, Mellert F, Welz A (2007) Detection of coronary arteries and evaluation of anastomoses with a commercially available $15-\mathrm{MHz}$, broadband, linear array transducer. Heart Surg Forum 10:E387-E391

33. Damp J, Zhao DX, Greelish J, Day G, Paris C, Corr B, Crosby S, Chrispin J, Jiramongkolchai, Byrne J (2006) Intra-operative completion angiography after cabg with immediate percutaneous or surgical revision of defects: one year experience from the vanderbilt hybrid catheterization and operating room. (Abstr). Scientific Sessions American Heart Association; presentation 2117

34. Kappert U, Schneider J, Cichon R, Gulielmos V, Tugtekin SM, Nicolai J, Matschke K, Schueler S (2001) Development of robotic enhanced endoscopic surgery for the treatment of coronary artery disease. Circulation 104(Suppl I):I-102-I-107
35. Mack MJ, Osborne JA, Shennib H (1998) Arterial graft patency in coronary artery bypass grafting: what do we really know? Ann Thorac Surg 66:1055-1059

36. Berger PB, Alderman EL, Nadel A, Schaff HV (1999) Frequency of early occlusion and stenosis in a left internal mammary artery to left anterior descending artery bypass graft after surgery through a median sternotomy on conventional bypass. Benchmark for minimally invasive direct coronary artery bypass. Circulation 100:2353-2358

37. PREVENT IV Investigators (2005) Efficacy and safety of edifoligide, an E2F transcription factor decoy, for prevention of vein graft failure following coronary artery bypass graft surgery PREVENT IV: a randomized controlled trial. JAMA 294:2446-2454

38. Siegel SB, White GH, Colman PD, Nelson RJ (1995) Intraoperative angioscopy for coronary bypass surgery. J Card Surg 10:210-220

39. Wolf RK, Falk V (2003) Intraoperative assessment of coronary artery bypass grafts. [Editorial] J Thorac Cardiovasc Surg 126:634-637

40. Balacumaraswami L, Abu-Omar Y, Anastasiadis K, Choudhary B, Pigott D, Yeong SK, Taggart DP (2004) Does off-pump total arterial grafting increase the incidence of intraoperative graft failure? J Thorac Cardiovasc Surg 128:238-244

41. Schachner T, Feuchtner GM, Bonatti J, Bonaros N, Oehlinger A, Gassner E, Pachinger O, Friedrich G (2007) Evaluation of robotic coronary surgery with intraoperative graft angiography and postoperative mulitislice computed tomography. Ann Thorac Surg 83:1361-1367

42. Goldman S, Zadina K, Moritz T, Ovitt T, Sethi G, Copeland JG, Thottapurathu L, Krasnicka B, Ellis N, Anderson RJ, Henderson W, VA Cooperative Study Group \#207/297/364 (2004) Long-term patency of saphenous vein and left internal mammary artery grafts after coronary artery bypass surgery. Results from a Department of Veteran Affairs cooperative study. J Am Coll Cardiol 44:2149-2156

43. Falk V, Walther T, Stein H, Jacobs S, Walther C, Rastan A, Wimmer-Greinecker G, Mohr FW (2003) Facilitated endoscopic beating heart coronary artery bypass grafting using a magnetic coupling device. J Thorac Cardiovasc Surg 126:1575-1579

44. Carrel T, Englberger L, Keller D, Windecker S, Meier B, Eckstein FS (2004) Clinical and angiographic results after mechanical connection for distal anastomosis in coronary surgery. J Thorac Cardiovasc Surg 127:1632-1640

45. Budde RPJ, Suyker WJL, Suyker PTW, Verlaan CWJ, Meijer R, Borst C, Gründeman PF (2005) Quality assessment of distal S ${ }^{2} \mathrm{AS}$ connector anastomosis by $13 \mathrm{MHz}$ epicardial ultrasound. Eur J Cardiothorac Surg 28:833-837 